\title{
A participação da sociedade civil nos consel hos de saúde e de políticas sociais no município de Piraí, RJ (2006)
}

\author{
The participation of civil society in health and social policy \\ councils in the city of Piraí, State of Rio de Janeiro (2006)
}

Gabriela Rieveres Borges deAndrade ${ }^{1}$

Jeni Vaitsman ${ }^{1}$

${ }^{1}$ Departamento de Ciências Sociais, Escola Nacional de SaúdePública, Fiocruz. R. Leopoldo Bulhões 1480, Manguinhos. 21041-210 Rio deJaneiro RJ. gandrade@ensp.fiocruz.br
Abstract Social policy councils began to be set up in municipalities in Brazil in the 1990s, first in the health care sector, then spreading to other sectors, for the purpose of including civil society in municipal policy management. Among the advances, studies revealed the formation of a network of government and non-government actors for the resolution of problems in the sector. Among the challenges, therewasthelimitation of the participation of government programs to acritical approval. This paper addresses the participation of councilors and representatives of ci vil society in the $\mathrm{H}$ ealth Council as being included in a network that includes councils and civil society organizations in a small municipality. Based on semistructured interviews with councilors representing civil society, two dimensions of participation are analyzed. The first is the relationship between demand for participation generated by the simultaneous activity of various sectorial councils and the participatory basis existing in the city. The second is the relationship between the issues that the respondents identified and their role as councilors. Lastly, the article discusses the potential of municipal councils in contributing to an intersectorial management of the city's problems.

Key words Health council, Social policy councils, M unicipality, Participation, Civil society, Intersectorial management
Resumo Os conselhos de políticas sociais come çaram a ser implantados nos municípios brasileirosdurante os anos de 1990, primeiro para o setor saúde e depois se espalhando para outros, com o propósito de incluir a sociedade civil na gestão das políticas municipais. Estudos apontam, entre os avanços, a formação de uma rede de atores governamentais e não governamentais para a resolução de problemas setoriaise, entre os desafios, a limitação da participação à aprovação acrítica de programas governamentais. Este artigo aborda a partici pação de consel heiros, representantes da sociedade civil, no conselho de saúde, como inserida em uma rede que envolve consel hos e organizações da sociedade civil, em um município pe queno. A partir de entrevistas com conselheiros representantes da sociedade civil, realizadas com um roteiro semiestruturado, analisa-se duas dimensões da participação: a relação entre demanda por participação gerada pela atividade simultânea de vários consel hos setoriais e a base participativa existente na cidade e a relação entre os problemas que os entrevistados identificam e a sua atuação como conselheiros. Por fim, 0 artigo discute o potencial dos consel hos municipais em contribuírem com uma gestão intersetorial dos problemas da cidade.

Palavras-chave Consel ho desaúde, Conselhos de políticas sociais, Município, Participação, Sociedade civil, Intersetorialidade 
Introdução

No Brasil, os Conselhos de políticas sociais foram criados com a Constituição Federal Brasileira de 1988 e a redemocratização do Estado, após 20 anos degovernos militares. A nova constituição introduziu mudanças abrangentes na área da proteção social, entre as quais a descentralização administrativa e financeira da gestão das políticas para o nível municipal e a introdução da gestão participativa através dos conse Ihos de políticas sociais. Formados por repre sentantes da sociedade civil e dos setores público e privado, os conselhos têm a atribuição de discutir e acompanhar a gestão das políticas públicas em cada nível de governo.

0 setor saúde foi o pioneiro da gestão participativa, pois o Sistema Ú nico de Saúde, o SUS, estabelecido na Constituição de 1988 e que garante 0 acesso universal a uma rede de serviços assistenciais de saúde públicos, foi fruto de um movimento de amplos setores da sociedade civil pela reforma sanitária. O SUS estabeleceu estratégias bem sucedidas de incentivos para a descentralização e para a criação de aparatos de gestão municipal, incluindo os Conselhos de Saúde atrelados às Secretarias M unicipais de Saúde. A criação de Conselhos de Saúde é uma das condições para a descentralização o que explica queaté o fim da década de 90 já tivessem sido estabelecidos Conselhos de Saúde em praticamente todos os municípios brasileiros.

Posteriormente, outros setoresincluíram conselhos gestores no seu aparato institucional re sultando em uma proliferação desses espaços que tem sido chamada de 'febre conselhista'. Embora existam diferenças na composição dos conselhos, em todos está prevista a participação de representantes do governo, do setor privado e da sociedade civil, de forma voluntária e não remunerada.

Ainda que seja consenso que os conselhos representam um aprimoramento da democracia da gestão pública, ao incluírem representantes da sociedade civil na administração das políticas públicas nos três níveis de governo, reforçando uma rede de interação entre atores governamentais e não governamentais e produzindo novas práticas para a resolução de problemas ${ }^{1-3}$, as análises de experiências locais apontam diversos de safios. Em muitos casos, a participação da sociedade civil tem selimitado a uma aprovação acrítica de programas governamentais $s^{46}$.

Contribuem para isso o não cumprimento de regras internas ao conselho, como a paridade da composição entre representantes da socieda- de civil e governo, o legado de cultura política autoritária efalta de cultura cívica ${ }^{7-9}$. Estabelecer o mesmo formato de participação em diferentes contextos e sem que haja correlação entre o número de conselhos eo de habitantes de um município também tem sido apontado como um desafio para a participação, na medida em que em muitos a sociedade civil não se encontra organizada o suficiente para fazer-se representar autônoma e consistentemente nesses espaços, 0 que fica mais visível nos de pequeno porte ${ }^{10}$.

Asimplicações de se estabelecer o mesmo formato participativo em diferentes setores e contextos têm sido ainda pouco discutidas. Este artigo levanta e discute algumas dessas questões em um município pequeno. Trata-se deum estudo exploratório que aborda a participação em conselhos como uma rede onde interagem diferentes atores e organizações e analisa o potencial e os desafios dos consel hos gestores de políticas sociais em contribuírem com uma gestão intersetorial dos problemas na cidade.

\section{Participação: consensos e dilemas}

A partir dos anos de 1990 cresce o consenso entre academia, movimentos sociais, políticos e agências internacionais sobre a importância da participação da sociedade civil em projetos de desenvolvimento ena gerência de políticas públicas. Essa convergência se baseia na ideia de que a participação contribui para o controle da gestão pública, coíbe o mau uso dos recursos, melhora o desempenho das políticas econfere legitimidade aos governos e às políticas ${ }^{11-14}$.

Agências internacionais passaram a incluir a participação como uma estratégia de ação em suas declarações, projetos e, em alguns casos, na sua política institucional oficial ${ }^{15}$. A participação nestes casos éentendida como um instrumento gerencial e como um meio de melhorar o desempenho de projetos e promover o desenvolvimento ${ }^{16}$.

No Brasil e na América Latina, a participação surge como demanda dos movimentos sociais como um instrumento para transformar estruturas e relações de poder e aprimorar a de mocracia. A participação dos cidadãos na gestão de programas governamentais, e não só nas eleições, é considerada um meio para transformar relações de poder e promover a interação entre governo e população com base na confiança ${ }^{17,18}$.

Com a proliferação de experiências participativas em diferentes contextos socioculturais, têm-se procurado elucidar as relações entre os métodos participativos e seus resultados, tanto 
no seu potencial de aprimorar a democracia quanto no de melhorar o desempenho de proje tos, programas e políticas ${ }^{19-24}$.

No caso de espaços criados pelo governo, corre-se o risco de a participação da sociedade civil ser ritualizada e pouco espontânea. Além disso, os espaços criados espontaneamente pelas comunidades podem ficar esvaziados e os movimentos sociais, percebendo a lógica defuncionamento do governo por dentro, podem acabar por assumir uma posição de defesa do governo em detrimento de uma posição mais reivindicativa e de pressão por melhorias para a população ${ }^{25-27}$. Também tem sido apontado que a influência de partidos políticos locais pode restringir a autonomia da participação da sociedade civi| ${ }^{28}$.

Apesar desses riscos e de outras limitações apontadas por análises de experiências participativas em curso, as quais têm gerado uma visão mais cética sobre o potencial da participação em melhorar o desempenho dos programas governamentais e aumentar a transparência no uso dos recursos, permanece o consenso em torno da importância da população estar inserida no planejamento das ações que as afetam. Estudos em contextos internacionais também mostram que a participação da comunidade tem sido de cisiva para garantir a cooperação entre setores e atores governamentais e não governamentais em endereçar problemas sociais e de saúde como dengue, imunização e saneamento, que demandam uma interação setorial ${ }^{29,30}$.

No Brasil, os conselhos de políticas sociais resultam das lutas pela democracia nas décadas de 1970 e 1980, eimplicam, hoje, em uma verdadeira engenharia institucional criada para promover a participação da soci edade civil, gerando uma diversidade de experiências. Estudos apontam problemas tais como escassez de debates e discussões antes da aprovação de orçamento, projetos e programas, falta de quorum nas reuniões, dificuldades para encontrar pessoas para participar e pouco interesse do setor governamental pela participação e interferência dos partidos políticos na participação8,31-33. Embora a legislação proíba a representação partidária dentro dos consel hos, redes formais einformais com partidos políticos podem levar a que certos indivíduos tenham mais interesse em participar do que outros.

Esses problemas têm sido atribuídos à falta de cultura cívica e à herança política autoritária, desigual dade de poder entre os consel heiros que representam a sociedade civil e os que representam o governo, baixo grau de organização da sociedade civil e a predominância de tarefas burocráticas em relação ao debate de questões da comunidade ${ }^{32-34}$.

Em experiências mais bem sucedidas, tem havido um aumento do capital social dos conseIheiros e um aprendizado sobre as políticas ${ }^{8,7,31}$. A interação entre atores com diferentes pontos de vista nos conselhos tem possibilitado o aumento da transparência da gestão das políticas e da base de legitimidade das políticas sociais ${ }^{1,9}$. Sublinha-se ainda, o potencial de contribuir com o estabel ecimento de al ianças intersetoriais para a implementação de programas sociais e de envolver a comunidade na identificação de problemas e na circulação de informação sobre os serviços disponívei $s^{35}$.

Este estudo identifica e discute al guns desafios para que este potencial se realize tomando como base a experiência bem sucedida do Conselho de Saúde do município de Piraí.

\section{Metodologia}

A pesquisa foi realizada em Piraí, município de 24 mil habitantes, localizado no Estado do Rio de Janeiro, na região Sudeste do Brasil. Tem um território de 505 km2 e 82\% da sua população reside em zona urbana ${ }^{36}$. É relativamente próspero economicamente, tendo sido classificado entre os 10 mais desenvolvidos entre os 92 municípios do Estado do Rio de Janeiro ${ }^{37}$, parte desse avanço devendo-se à instalação de novas indústrias nos últimos dez anos.

Em 2005, o município recebeu o prêmio Top Seven Inteligent Communities- As 7 cidadesmais inteligentes do mundo, pela instalação de uma rede deacesso livrea internet na cidadee a distribuição de computadores a todos os alunos da rede de ensino municipal. No setor saúde, conta com doze (12) Postos de Saúde com equipes de Programa de Saúde da Família e um hospital conveniado e tem investido uma porcentagem maior de recursos municipais do que o mínimo de $15 \%$ definido constitucionalmente.

O município também ganhou visibilidade, junto com outras experiências de boas práticas municipais no Brasil, após receber o Prêmio Gestão Pública e Cidadania pelo Programa de Desenvolvimento Local dePiraí ${ }^{38}$, em partepelo seu foco na incorporação da população na gestão das políticas.

O contexto político de Piraí, onde o mesmo partido político permanece no poder desde 1997 sem encontrar muita oposição e gozando de lar- 
ga aprovação pública, pareceter contribuído para a produção de um ambiente político local com pouco conflito em questões substantivas. A escolha deste município para o estudo deveu-se à cidade ter conselhos para quase todos os setores de políticas econtar com uma sociedade civil atuantee com uma diversidade de organizações sem fins lucrativos.

0 estudo de caso éaqui compreendido como uma abordagem que oferece possibilidades de análises em uma perspectiva múltipla e que considera não apenas a voz e a perspectiva dos atores ou grupos, mas também, a interação entre eles $^{39}$. N esteartigo, a participação em consel hosé vista como uma rede, onde os indivíduos que nela interagem possuem múltiplasfiliações eparticipam em vários espaços não governamentaise governamentais. Esta abordagem possibilitou compreender o Conselho de Saúde inserido em uma rede de conselhos ede consel heiros que atuam sobre um conjunto de temas na cidade.

Neste sentido, procurou-se ampliar a compreensão sobre os fatores que influem na participação nos consel hos no nível local, identificando relações específicas que podem ser traduzidas em variáveis em outros estudos. Trata-se de um estudo de caso instrumental, o qual possibilita explorar novos elementos para a compreensão de um problema ${ }^{40}$.

A principal fonte de informações foram entrevistas realizadas com dezenove (19) consel heiros, entre maio e agosto de 2006, que participam ou que já participaram do Conselho de Saúde e que também atuam em outros conselhos na cidade. Através de um roteiro semiestruturado foram abordadas questões sobre as atividades do entrevistado (1) como conselheiro, tais como em quantos conselhos participa, tempo de conselho, atividades como conselheiro e dificuldades encontradas para exercer suas atividades; e (2) como líder comunitário, tais como, atuação como líder comunitário e informações sobre a organização que representa (frequência de reuniões da organização, público-alvo, número de componentes/associados, ações desenvolvidas, avanços e problemas da organização) ${ }^{41}$.

Os entrevistados foram identificados na ata de composição do Conselho de Saúde e, na medida em que eram entrevistados, indicavam outros consel heiros eorganizações sem fins lucrativos da cidade.

Também foram entrevistados representantes de cinco secretarias: de saúde, do meio ambiente, de educação, de assistência social e da cidadea fim de compreender como os consel hos des- sas secretarias funcionam e interagem e foram examinadas atas de criação dos conselhos e das organizações da sociedade civil, afim de verificar a data de criação das organizações e dos conseIhos (que não necessariamente coincide com o início defuncionamento do conselho) bem como as atas das reuniões do Conselho de Saúde do ano corrente, a fim deaveriguar as contribuições dos consel heiros da sociedade civil registradas.

As entrevistas foram gravadas com autorização dos entrevistados, que assinaram um Termo de Consentimento Informado ( $\mathrm{TCl}$ ) aprovado pelo Comitê de Ética da Escola Nacional de Saúde Pública. Foi esclarecido no TCI que como os entrevistados são pessoas conhecidas na cidade, poderiam vir a ser identificados pelos seus pares na divul gação dos resultados, mas que não seriam identificados pelos seus nomes.

As entrevistas transcritas foram lidas, categorizadas eanalisadas sendo discutidas aqui duas das questões que emergiram dessas análises: a demanda por participação e a seletividade dos problemas levados aos conselhos.

\section{A demanda por participação}

O Conselho de Saúde de Piraí foi criado no ano de 1991 e, em seguida, os deAssistência Social e o dos Direitos da Criança e do Adolescente, ambos ligados à Secretaria de Assistência Social. Durante os anos 2000 foram criados mais doze (12), ligados a quatro secretarias, totalizando quinze (15) no final de 2005 (Quadro 1).

Cerca de cinco desses conselhos foram criados somente no papel ou não funcionam regularmente, geralmente por falta de quórum nas reuniões. Está previsto nos regimentos internos dos conselhos reuniões uma vez por mês e podem acontecer reuniões extraordinárias, caso necessário. Entre as razões apontadas pelos conselheiros para o não comparecimento nas reuniões, é que falta de algum tipo de controle caso o conselheiro não vá. Vocêvai não vai, não tem punição nenhuma. Aí fica essa coisa abandonada. (entrevista 16 - conselheiro de saúde).

Também foram apontadas a falta de interesse tanto da parte governamental quanto da sociedade civil em determinado conselho, Chegava lá, cadê a parte governamental? Não veio. Cadêa partedasentidades? Então aquilo desanimou a gente até mesmo de concorrer (entrevista 03 - conseIheiro do CM DCA); ea criação de consel hos ape nas para cumprir uma determinação do nível fe deral, $\mathrm{N}$ em semprefuncionam, porque muitos são criados muito rápido, sem um planejamento maior (entrevista 14 - conselheiro de saúde). 
Ainda assim, o número de conselhos em que cada entrevistado participa tem aumentado. No momento da pesquisa a média de conselhos por entrevistado era de 2,3 conselhos. Perguntados sobre em quantos conselhos participavam no mandato anterior, essa média caiu para um conselho por entrevistado, ou seja, o número médio de conselhos por conselheiro aumentou para to-

Quadro 1. Conselhos Gestores de Políticas Sociais em Piraí, 2005.

\begin{tabular}{|l|l|c|}
\hline \multicolumn{1}{|c|}{ Secretaria } & \multicolumn{1}{|c|}{ Consel ho } & $\begin{array}{c}\text { Ano de } \\
\text { criação }\end{array}$ \\
\hline Saúde & Saúde & 1991 \\
& Unidade de saúde (duas) & 2004 \\
\hline Assistência & Assistência Social & 1993 \\
Social & Criança e adolescente & 1993 \\
& Idosos & 2000 \\
& Mulher & 2004 \\
& Segurança Alimentar & 2004 \\
& Portadores de deficiência & 2005 \\
& Antidrogas & 2005 \\
\hline Educação & Educação & 2001 \\
& Orçamento & 2001 \\
& M erenda Escolar & 2001 \\
\hline Planejamento & Cidade & 2004 \\
\hline M eio ambiente & M eio ambiente & 2004 \\
\hline
\end{tabular}

Fonte: as autoras ${ }^{41}$ dos, exceto um conselheiro (Tabela 1). Os líderes comunitários têm diferentes interesses em fazer parte de um determinado conselho, que passam pela afinidade do tema do conselho com o da organização que representam, pela afinidadecom os representantes do governo emesmo pelo bom desempenho do setor.

A falta de organização da sociedade civil costuma ser apontada como uma razão para o funcionamento precário dos conselhos, o que, no entanto, não éo caso de Piraí. A primeira organização sem fins lucrativos de Piraí foi criada no início da década de 1980 para fins religiosos e al guns de seus membros começaram a desenvolver ações, principalmente de saúde e habitação, junto a uma comunidade carente. Essa atuação, que durou cerca de dois anos, Mudou a história daquele bairro. Ascrianças estavam morren do com doenças, nós fomos nas casas, ar rumamos as casas das pessoas voluntariamente, pedindo para um, tirando do próprio bolso (entrevista 14 - conseIheiro de saúde).

No início dos anos 90 chegou à cidade uma organização internacional que já atuava em outras cidades brasileiras, voltada ao combateà desnutrição infantil. Suas ações representaram um tipo de atuação mais técnica e sistemática, com métodos definidos e, naquele momento, ainda pouca interação com o governo local Q uem subiu o morro, ia para o alto lá, era a nome da organização. Fomos enquanto acadêmicos de enfermagem. No primeiro ano a gente veio com o dinheiro da organização, então, a gentepôdepagar a alimenta-

Tabela 1. Número de conselhos em que os conselheiros participavam antes de 2005 (1) e em 2005 (2).

\begin{tabular}{clcrr}
\hline Entrevistado & \multicolumn{1}{c}{ Tipo da organização } & $\begin{array}{c}\mathrm{N} \text { - Consel hos } \\
(1)\end{array}$ & $\begin{array}{c}\text { No Conselhos } \\
(2)\end{array}$ & $(2-1)$ \\
\hline 1 & Bairro & 0 & 2 & +2 \\
2 & Crianças com necessidades especiais & 2 & 5 & +3 \\
3 & Bairro & 1 & 1 & 0 \\
4 & Bairro & 0 & 1 & +1 \\
5 & Gestantes e crianças & 1 & 6 & +5 \\
6 & Bairro & 0 & 1 & +1 \\
7 & Bairro & 1 & 2 & -2 \\
8 & Bairro & 2 & 3 & +1 \\
9 & Idosos & 0 & 2 & +2 \\
10 & Bairro & 0 & 2 & +2 \\
11 & Bairro & 3 & 1 & -2 \\
12 & Rádio Comunitária & 0 & 1 & +1 \\
13 & Meio ambiente & 0 & 3 & +3 \\
14 & Mulher & 0 & 2 & +2
\end{tabular}

Fonte: as autoras ${ }^{41}$ 
ção dos acadêmicos de enfermagem [...]. Então era superinteressante né, porque a organização podia financiar a passagem eo al moço deles. A gentefazia toda essa cobertura dessa criançada de 0 a 4 anos. (entrevista 04-consel heiro de saúde).

Com o boom das Associações de M oradores, na metade dos anos 90 , a interação com o governo local intensificou-se. N esta época, já havia sido criado o Conselho de Saúde, mas as Associações de M oradores ainda não tinham assento neste conselho. Somente a partir de 1997, com a estruturação da Secretaria de Assistência Social de Piraí, quepassou a assessorar juridicamenteas Associaç̃es de M oradores, organizando a documentação necessária para que obtivessem registro como entidade sem fins lucrativos, essas associações passaram a integrar o Consel ho de Saúde.

Já nos anos 2000, novas associações com diferentes graus de estruturação, formas de atuação e objetivos, tais como recreação para a terceiraidadee proteção erecuperação do meio ambiente, surgiram na cidade. Em resumo, a socie dade civil de Piraí não só tem organizações atuantes como novas continuam surgindo, passando a fazer parte da composição de algum conse Iho quase que imediatamente.

A Tabela 2 mostra o intervalo de tempo entre o ano de criação da organização e sua inserção em conselhos que tem se tornado cada vez menor. Nos casos onde não aparece diferença entre 0 ano em que a organização foi criada e a participação em conselhos, os líderes comunitários já participavam antes mesmo da criação da orga- nização, como ouvintes ou representando outro segmento.

Esses dados apontam para um tipo de interação que se intensifica em Piraí, entre organizações da sociedade civil, principalmente Associações de M oradores, e governo local, através dos conselhos, o que implica em riscos apontados pela literatura sobre participação, tais como perda da autonomia e da capacidade de assumir uma posição mais crítica da sociedade civil frente ao governo. Não se pode afirmar, com base nesses dados, que a sociedade civil de Piraí tenha perdido sua autonomia e capacidade crítica, já que as organizações e conselheiros são muito diferentes na sua forma de atuação, mas chama a atenção o rápido aumento do número de conselhos produzindo um excesso de demanda por participação sobre os membros das organizações da sociedade civil. Você encontra as mesmas pessoas em todos os conselhos, companheiros de consel hos, no caso. (entrevista 04- conselheiro do CM DCA).

Tal demanda tem consequências em um município com uma experiência bem sucedida de participação, principalmente no Conselho de Saúde. Muitos dos entrevistados participam desse conselho há muito tempo e ganharam experiência. Porém, é possível observar um cansaço desses conselheiros bem como uma dificuldade em renovar os quadros de representantes da sociedade civil no Conselho de Saúde. Tem outros conselhos que chamam para participar, mas eu tô esperando que outras pessoas se interessem, para não ficar essa coisa deM as só ele participa de tudo.

Tabela 2. Público-alvo da organização, ano de criação e intervalo entre o ano de criação e o de entrada em um conselho.

\begin{tabular}{lccr}
\hline \multicolumn{1}{c}{ Público-alvo } & $\begin{array}{c}\text { Criação da } \\
\text { organização (1) }\end{array}$ & $\begin{array}{c}\text { Início da participação em } \\
\text { Conselhos (2) }\end{array}$ & $(2-1)$ \\
\hline 1. Bairro & 1983 & 2004 & +21 \\
2. Crianças com necessidades especiais & 1987 & 1999 & +12 \\
3.Bairro & 1991 & 2001 & +10 \\
4. Bairro & 1992 & 2005 & +13 \\
5. Gestantes e crianças & 1995 & 1998 & +03 \\
6. Bairro & 1996 & 2004 & +08 \\
7. Bairro & 1996 & 1996 & 0 \\
8. Bairro & 1999 & 1994 & -05 \\
9. Idosos & 1999 & 2003 & +04 \\
10. Bairro & 2000 & 2004 & +04 \\
11. Bairro & 2001 & 2001 & 0 \\
12. Rádio Comunitária & 2001 & 2004 & +03 \\
13. M eio ambiente & 2002 & 2002 & 0 \\
14. Mulher & 2005 & 2005 & 0
\end{tabular}

Fonte: as autoras ${ }^{41}$ 
Ficar uma hora, duas participando é complicado. (entrevista 01 - conselheiro de saúde).

\section{A seletividade de problemas}

O Conselho de Saúde dePiraí, por seu tempo defuncionamento e sua história, éum marco na promoção de uma cultura participativa na cidade, o que se manifesta, por exemplo, na Conferência M unicipal de Saúde realizada a cada quatro anos, reunindo cerca de quinhentas pessoas, entre representantes da sociedadecivil, governo e setor privado. N essa ocasião se discutem as políticas de saú de da cidade e se escolhem as entidades da sociedade civil que terão assento no conselho nos anos subsequentes. Os conselheiros, no entanto, são renovados a cada dois anos.

A atividade que os conselheiros da sociedade civil realizam com mais frequência émonitorar os serviços de saúde, fazendo visitas e ouvindo as reclamações dos pacientes: Devido ao meu trabalho como consel heiro, eu passo muito por esses locais (unidades de saúde). Às vezes alguém fala Está faltando remédio em tal lugar; ou Está tendo problema no Posto tal. (entrevista 01 - consel heiro de saúde).

$\mathrm{N}$ as suas ati vidades como líderes comunitários, os entrevistados identificam os problemas de diversas formas e se interessam menos por qual setor ou secretaria determinado problema está ligado e mais pelo quanto o problema incomoda a ele e às pessoas com as quais lida no seu cotidiano (Quadro 2). Problemas relacionados à saúde, meio ambiente etransporteforam identificados através de diversos meios: conversas com profissionais do setor ou com representante governamental, em reuniões do consel ho e, principalmente, na própria vivência do consel heiro na sua rua, bairro, cidade.

Quatro, entre os problemas levantados, foram identificados através da atuação como conselhei ro e cinco foram encaminhados aos conseIhos. A maioria dos problemas foi encaminhada de outras formas, sendo esses, na sua maioria, problemas relativos a conselhos que não estão atuando com regularidade. Dos dezesseis problemas encaminhados, oito foram considerados resolvidos. Os problemas levados aos consel hos são restritos ao foco específico do conselho. Problemas que afetam a saúde da população tais como "queimadas", "esgotamento inadequado" e "poluição de rios enascentes" não são endereçados ao conselho de saúde.

Entre as formas de encaminhamento foram organizadas petições ou foi feito um contato pessoal com o prefeito, o vice-prefeito ou com os gestores setoriais. Este tipo de relação mais próxima entre a prefeitura e os líderes comunitários não é incomum em cidades pequenas, facilitada por uma maior informalidade nas relações. Embora iniciativas formais como ação pública e ato público não sejam descartadas pelos líderes comunitários, que conhecem e consideram essas possibilidades, não é costume lançar mão desses recursos. Eles preferem resolver os problemas por ações que gerem menos conflito, através de contatos pessoais ou em fóruns específicos, quando existem e funcionam apropriadamente.

O olhar do representante da sociedade civil, principalmente daqueles ligados às associações de bairro é voltado para os problemas no bairro, da comunidade e da cidade de uma forma não setorial. Esses problemas são identificados a partir da rede na qual estão inseridos, redeesta composta por funcionários da prefeitura, políticos locais, donas de casa, aposentados, trabalhadores do campo, outros líderes comunitários e experiência própria no bairro onderesidem. É através dessa experiência como líderes comunitários, que os consel heiros representantes da sociedade civil podem contribuir com maior frequência nos conselhos, ou seja, como um intermediário entre o consel ho e a comunidade.

\section{Conclusões}

Este artigo procurou analisar implicações da implantação de consel hos setoriais em um município pequeno a fim de entender alguns dos avanços e desafios do desenho participativo da gestão das políticas sociais estabelecido pela Constituição de 1988.

Análises sobre espaços participativos criados pelo governo apontam para a dificuldade em encontrar pessoas disponíveis para participar e para o risco de desmobilização de espaços criados espontaneamente pela sociedade civil. No caso de Piraí, a prefeitura local ajudou a estruturar as organizações sem fins lucrativos que já existiam e, 0 funcionamento dos consel hos, motivou a criação de outras. No entanto, o rápido aumento do número de conselhos sem o proporcional aumento de uma base participativa, ou seja, do número de organizações e de pessoas envolvidas, tem implicado em al guns limites nessa forma de interação entresociedade civil egoverno.

Pela identificação deuma participação através de diferentes conselhos setoriaisna cidadefoi possível levantar alguns desses limites. Os consel hos de políticas mais antigos incluíram novos atores 
Quadro 2. Problema identificado, meio de identificação, de encaminhamento e situação quanto à resolução.

\begin{tabular}{|c|c|c|c|}
\hline Problema identificado & M eio de identificação & Encaminhamento & Situação \\
\hline $\begin{array}{l}\text { 1.Falta de transporte } \\
\text { público }\end{array}$ & $\begin{array}{l}\text { Contato com outras } \\
\text { organizações }\end{array}$ & Reclamação na mídia & Resolvido \\
\hline $\begin{array}{l}\text { 2. Calçamento de rua } \\
\text { inadequado }\end{array}$ & $\begin{array}{l}\text { Representante do governo } \\
\text { solicitou opinião do líder } \\
\text { comunitário sobre o tema }\end{array}$ & $\begin{array}{l}\text { Falou diretamente com o representane do } \\
\text { governo }\end{array}$ & Resolvido \\
\hline 3. Falta de sinalização & Experiência própria & $\begin{array}{l}\text { M obilização nas reuniões promovidas pelo } \\
\text { Conselho da Cidade }\end{array}$ & Resolvido \\
\hline 4. Valor da conta de água & Experiência própria & Estudando para entrar com ação & $\begin{array}{l}\text { Sendo } \\
\text { encaminhado }\end{array}$ \\
\hline $\begin{array}{l}\text { 5. Utilização sem } \\
\text { controle de água de mina }\end{array}$ & Experiência própria & Estudando forma de encaminhar & $\begin{array}{l}\text { Sendo } \\
\text { encaminhado }\end{array}$ \\
\hline $\begin{array}{l}\text { 6. Esgotamento } \\
\text { inadequado }\end{array}$ & Experiência própria & Recolhendo assinaturas para a petição & $\begin{array}{l}\text { Sendo } \\
\text { encaminhado }\end{array}$ \\
\hline $\begin{array}{l}\text { 7. Poluição de rios e } \\
\text { nascentes }\end{array}$ & Experiência própria & $\begin{array}{l}\text { Buscando parcerias para lutar pelo fim dessa } \\
\text { poluição }\end{array}$ & $\begin{array}{l}\text { Sendo } \\
\text { encaminhado }\end{array}$ \\
\hline 8. Queimadas & Experiência própria & $\begin{array}{l}\text { Conversa com as pessoas que fazem queimadas e } \\
\text { solicitou mai ores providências à Secretaria de } \\
\text { M eio Ambiente }\end{array}$ & Não resolvido \\
\hline 9. Lixo nas ruas & Experiência própria & $\begin{array}{l}\text { Comunica ao serviço responsável e conversa com } \\
\text { as pessoas quando as vê jogando lixo nas ruas }\end{array}$ & Resolvido \\
\hline 10. Ratos & $\begin{array}{l}\text { Conversa com funcionário } \\
\text { da Vigilância Sanitária }\end{array}$ & Parceria entre Vigilância Sanitária e AMs & Resolvido \\
\hline $\begin{array}{l}\text { 11. Fila dupla na unidade } \\
\text { de saúde }\end{array}$ & $\begin{array}{l}\text { Visita à unidade como } \\
\text { Conselheiro de Saúde }\end{array}$ & Reclamação no Conselho de Saúde & Resolvido \\
\hline 12. Sumiço de exames & $\begin{array}{l}\text { Reclamação de usuário } \\
\text { complaint }\end{array}$ & Conversou com funcionário responsável & Resolvido \\
\hline $\begin{array}{l}\text { 13. M edicamentos fora } \\
\text { da validade }\end{array}$ & $\begin{array}{l}\text { Reclamação de usuário do } \\
\text { serviço de saúde }\end{array}$ & Conversou com funcionário responsável & Não resolvido \\
\hline $\begin{array}{l}\text { 14. Ausência de } \\
\text { Delegacia da Mulher }\end{array}$ & Contato com mulheres & Levou o problema ao Conselho da Mulher & Não resolvido \\
\hline 15. Pobreza & $\begin{array}{l}\text { Contato com outras } \\
\text { organizações }\end{array}$ & $\begin{array}{l}\text { Proposta de projeto em parceria com a } \\
\text { Prefeitura }\end{array}$ & Não resolvido \\
\hline $\begin{array}{l}\text { 16. Uso de drogas ilegais } \\
\text { por menores de idade }\end{array}$ & Experiência própria & Levou o problema para o CM DCA & Não resolvido \\
\hline $\begin{array}{l}\text { 17. Interpretação } \\
\text { inadequada do Estatuto } \\
\text { da Criança }\end{array}$ & Experiência própria & Levou o problema para o CMDCA & Não resolvido \\
\hline $\begin{array}{l}\text { 18. Acesso ao ônibus } \\
\text { escolar }\end{array}$ & Experiência própria & Recolhendo assinaturas para petição & Não resolvido \\
\hline 19. Falta de área de lazer & Experiência própria & Reclamou com representante do governo & Não resolvido \\
\hline $\begin{array}{l}\text { 20. Falta de apoio ao } \\
\text { esporte }\end{array}$ & Experiência própria & Reclamou com representante do governo & Não resolvido \\
\hline
\end{tabular}

Fonte: as autoras ${ }^{41}$ 
no processo de gestão das políticas setoriais, mas encontram dificuldades para renovar seus membros a cada dois anos, bem como para qualificar os novos conselheiros. A existência simultânea de vários conselhos atuando na cidade tem aumentado a demanda por participação gerando uma concorrência por conselheiros.

Comparativamente a outros municípios de porte similar, vários indicadores referentes à organização do setor saúde, como orçamento, cobertura e condições de gestão, apresentam um bom desempenho em Piraí. Contudo, ainda que as políticas de saúde estejam relativamente bem estruturadas no município, para que os próprios indicadores melhorem, seria preciso maior integração com outras políticas so ciais. Porém, 0 desenho setorial de participação reproduz a fragmentação das políticas e os conselhos não têm constituído como fóruns integradores.

Estes resultados levam a refletir sobre os trade-offs em relação aos papéis que se espera dos

\section{Colaboradores}

GRB Andrade e J Vaitsman participaram igualmente de todas as etapas de elaboração do artigo. consel heiros representantes da sociedade civil: se uma atuação cada vez mais especializada em um setor, como o atual desenho da política vem se configurando; ou uma outra que, baseada na própria experiência comunitária dos conselheiros deveria possibilitar uma ação mais abrangente sobre um conjunto articulado e complexo de fenômenos que ultrapassam os limites setoriais.

Os achados deste estudo sugerem que as análises so bre conselhos devem levar em conta o contexto local em que se dá a participação, o que significa enten der a dinâmica e as articulações estabelecidas entre os vários atores envolvidos em uma rede participativa e não somente o consel ho enquanto um espaço circunscrito a um setor de políticas. Tal redeimplica em pressões, deum lado, para que mais pessoas sejam inseridas no processo participativo e de outro, que os conselhos se tornem mais aptos a debaterem e desenvolverem ações intersetoriais. Esteé um potencial que a inclusão da sociedade civil na gestão anuncia.

\section{Referências}

1. Coelho V, Andrade I, M ontoya M. Deliberative fora and the democratisation of Social Policies in Brazil. IDS Bulletin 2002; 33(2):65-73.

2. Cornwall A, Shankland A. Engaging citizens: lessons from building Brazil's national health system. Soc Scien M ed 2008; 66(10):2173-2184.

3. Abers R, Keck M. Representando a diversidade: Estado, sociedade e "relações fecundas" nos conseIhos gestores. Caderno CRH 2008; 21(52):99-112.

4. Correia M. Que controle social? Os conselhos de saúde como instrumento. Rio de Janeiro: Editora Fiocruz; 2000.

5. Dagnino E. Sociedade civil, espaços públicos e a construção democrática no Brasil: limites e possibilidade. In: Dagnino E, organizadora. Sociedade civil e espaços públicos no Brasil. São Paulo: Paz e Terra; 2002. p. 279-301.

6. Guizardi L, Pinheiro R. Dilemas culturais, sociais e políticos da participação dos movimentos sociais nos Conselhos de Saúde. Cien Saude Colet 2006; 11(3):797-805.

7. Labra M. Capital social y consejos de salud en Brasil? Un círculo virtuoso? Cad Saude Publica 2002; 18(Supl.):47-55. 
8. Fuks M, Perissinotto R. Recursos, decisão e poder Conselhos gestores de políticas públicas em Curitiba. Rev Bras Cien Soc 2006; 21(60):67-81.

9. Côrtes S. Céticos e esperançosos: perspectivas da literatura sobre participação e governança na área da saúde. In: Pinheiro R, M attos R, organizadores. Gestão em Redes: práticas de avaliação, formação e participação na saúde. Rio de Janeiro: CEPESC; 2006. p. 311-342.

10. Dombrowski O. Poder local, hegemonia e disputa: os consel hos municipais em pequenos municípios do interior. Rev Sociol Polit 2008; 16(30):269-281.

11. Evans P. Government Action, Social Capital and Development: Reviewing the Evidence on Synergy. World Development 1996; 24(6):1119-1132.

12. Schneider H. Participatory governance: the missing link for poverty reduction.OECD Development Centre: Policy Briefs [serial on the Internet] 1999 [cited $2006 \mathrm{M}$ ar 15]; 17: [about 31 p.]. Available from: http://www.oecd-ilibrary.org.

13. Putnam R. Comunidade e democracia: a experiência da Itália moderna. 2a Edição. Rio de Janeiro: Editora FGV; 2000

14. Morgan L. Community participation in health: perpetual allure, persistent challenge. Health Policy Planning 2000; 16:221-230

15. Kliksberg, B. Six unconventional theses about participation. Intern Review Admin Sci 2000; 66(1):161174.

16. Bishop P, Davis G. Mapping Public Participation in Policy Choices. Austr J Publ Admin 2002; 6(1):1429.

17. Tendler J, Freedheim S. Trust in a Rent-Seeking World: Health and Government Transformed in Northeast Brazil. World Development 1994; 22:17711791.

18. Carvalho A. Conselho de Saúde no Brasil: participação cidadã e controle social. Rio de Janeiro: FASE, IBAM; 1995.

19. Avritzer L, Santos B. Para ampliar o cânone democrático. In: Santos B, organizador, Democratizar a democracia. Rio de Janeiro: Civilização Brasileira; 2002. p. 43-82.

20. Holmes T, Scoones I. Participatory environmental policy processes: experiences from North and South. IDS Working Paper 2000; 113:1-62.

21. Cornwall A. M aking spaces, changing places: situating participation in development. IDS Working Paper 2002; 170:1-43.

22. Abelson J, Forest P, Eyles J, Smith P, Martin E, Gauvin F. Deliberations about deliberative methods: issues in the design and evaluation of public participation processes. Soc Sci M ed 2003; 57(2):239-251.

23. Thurston W, Mackean G, Vollman A, Casebeer $A$, Weber M, Maloff B, Bader J. Public participation in regional health policy: a theoretical framework. Health Policy 2005; 73(3):237-252.

24. Kuruvilla S. CSO Participation in health, research and policy: a review of models, mechanisms and measures. Working Paper ODS 2005; 251:1-42.

25. White S. Depoliticising development: the uses and abuses of participation. Development in Practice 1996; $6(1): 6-15$.
26. Cleaver F. Paradoxes of participation: questioning participatory approaches to development. J Int Development 1999; 11:597-612.

27. Cooke B, Kothari U. Participation: the new tyranny? London: Zed Books; 2001.

28. Montambeault F. Overcoming clientelism through local participatory institutions in M exico: what type of participation? Latin American Politics and Society 2011; 53(1):91-124.

29. Brown L, Ashman D. Participation, social capital, and intersectoral problem solving: African and Asian Cases. World Development 1996; 24(9):1467-1479.

30. Sanchez L, Perez D, Pérez T, Sosa G; Kouri G, Boelaert M, Van der Stuyft P. Intersectoral coordination in Aedes Aegypti control. A pilot Project in Havana City, Cuba. TM \& IH 2005; 10(1):82-91.

31. Coelho V. Brazil's health councils: the challenge of building participatory political institutions. IDS Bulletin 2004; 35(2):33-39.

32. Labra M, Figueiredo J. Associativismo, participação e cultura cívica: o potencial dos Conselhos de Saúde. Cien Saude Colet 2002; 7(3):537-547.

33. Côrtes S. Os Conselhos Municipais de Saúde: a possibilidade dos usuários participarem e os determinantes da participação. Cien Saude Colet 1998; 3(1):5-17.

34. Fuks M, Perissinotto R. Recursos, decisão e poder: conselhos gestores de políticas públicas em Curitiba. Rev Bras Cien Soc 2006; 21(60):67-81.

35. Junqueira L. N ovas formas de gestão na saúde: descentralização e intersetorialidade. Saúde e Sociedade 1997; 6(2):31-46.

36. Instituto Brasileiro de Geografia e Estatística (IBGE). Pesquisa de informações básicas municipais 2005. Rio de Janeiro: IBGE; 2006

37. Federação das Indústrias do Estado do Rio de Janeiro (Firjan). Índice Firjan de desenvolvimento municipal (IFDM). Rio de Janeiro: Firjan; 2006.

38. Silva L. Programa de desenvolvimento local de Piraí. In: Barbosa $H$, Spink P, organizadores. 20 Expe riências de gestão pública e cidadania - Ciclo premiação 2001. São Paulo: Programa Gestão Pública e Cidadania; 2002. p. 199-213.

39. Stake R. Case Studies. In: Denzin N, Lincoln $Y$, editors. $\mathrm{H}$ andbook of qualitative research. Thousand Oaks: Sage Publications; 1994. p. 236-247.

40. Tellis W. Introduction to case study. The Qualitative Report [serial in the Internet] 1997 Jul [cited 2006 Jan. 10]; 3(2): [about 14 p.]. Available from: http://www.nova.edu/ssss/QR/Q R3-2/tellis1.html.

41. Andrade G. A dinâmica da participação da sociedade civil em conselhos de políticas sociais no município de Piraí [tese]. Rio de Janeiro: Fiocruz; 2007.

Artigo apresentado em 04/06/2012

Aprovado em 18/08/2012

Versão final apresentada em 11/09/2012 